\title{
Innovative Pharmacological Therapies for the Hemophilias Not Based on Deficient Factor Replacement
}

\author{
Pier Mannuccio Mannucci, MD ${ }^{1}$ Maria Elisa Mancuso, MD, PhD ${ }^{1}$ Elena Santagostino, MD, PhD ${ }^{1}$ \\ Massimo Franchini, MD² \\ ${ }^{1}$ Angelo Bianchi Bonomi Hemophilia and Thrombosis Center, \\ Fondazione IRCCS Ca' Granda-Ospedale Maggiore Policlinico, \\ Milan, Italy \\ 2 Department of Transfusion Medicine and Hematology, Carlo Poma \\ Hospital, Mantova, Italy \\ Semin Thromb Hemost 2016;42:526-532.

\begin{abstract}
Address for correspondence Pier Mannuccio Mannucci, MD, Fondazione IRCCS Ca' Granda Ospedale Maggiore Policlinico, Via Pace 9, Milan, Italy (e-mail: piermannuccio.mannucci@policlinico.mi.it).
\end{abstract}

\begin{abstract}
Keywords

- hemostatic agents

- ACE910

- concizumab

- antithrombin

- FV variant

- FX variant

In recent years, advances in the pharmacological treatment of hemophilias $A$ and $B$ have mainly focused on the development of long-acting factor (F) VIII and FIX products. Alternative approaches not based on the replacement of the missing factor have also been explored, with the aim of producing therapeutic agents with reduced immunogenicity and yet equally effective in patients with or without inhibitors. These new classes of hemostatic agents act mainly by bypassing the need of FVIII and FIX in tenase formation, quenching anticoagulant pathways, enhancing the activity of some coagulation factors or stabilizing the fibrin clot. Current knowledge on the status of development of these novel molecules is summarized in this narrative review. We also surmise that the main interests for these products not based on the replacement of FVIII or FIX in deficient patients pertain to the potential for bleeding prevention in inhibitor patients, an earlier and easier prophylaxis implementation thanks to subcutaneous administration and prolonged half-life, and a low immunogenicity with the potential for prevention of inhibitor development in high-risk patients.
\end{abstract}

Hemophilias A and B are X-linked, recessive bleeding disorders resulting from the impaired deficiency or dysfunction of coagulation factor (F)VIII and FIX. ${ }^{1,2}$ The prevalence of hemophilia $A$ is 1 in 5,000 male live births and that of hemophilia $B$ is 1 in $30,000 .^{3}$ Disease classification is based on plasma FVIII and FIX levels, with $<1 \%$ factor level of normal defined as severe, 1 to $5 \%$ moderately severe, and $>5$ to $<40 \%$ mild disease. ${ }^{4}$ The main clinical signs are the occurrence of bleeding manifestations, which may be spontaneous, especially in severe hemophilia. Hemorrhages most commonly affect large joints (ankles, knees, and elbows), leading to the development of arthropathy, which severely impairs mobility and quality of life. Bleeding may also occur in soft tissues and (more seldom) in the gastrointestinal tract and central nervous system. ${ }^{5,6}$ Hemorrhages are treated with coagulation factor concentrates (replacement therapy), plasma-derived or recombinant. ${ }^{7}$ Prophylaxis of bleeding, involving the regular infusion of the deficient coagulation factor, is the mainstay of hemophilia care because its early implementation reduces the risk of joint bleeding and the resulting development of arthropathy, allowing patients to lead a life comparable to that of healthy individuals. 8,9

The most severe complication associated with FVIII and FIX replacement therapy is the development of inhibitory alloantibodies against FVIII or FIX, affecting at least one-third of patients with severe hemophilia A and approximately 3 to 5\% published online May 5, 2016
Issue Theme Controversies in Inherited Bleeding Disorders; Guest Editors: Antonio Coppola, MD, Massimo Franchini, MD, and Annarita Tagliaferri, MD.
Copyright $\odot 2016$ by Thieme Medical Publishers, Inc., 333 Seventh Avenue, New York, NY 10001, USA.

Tel: +1(212) 584-4662.
DOI http://dx.doi.org/ 10.1055/s-0036-1571310. ISSN 0094-6176. 
of those with severe hemophilia B. ${ }^{10,11}$ These inhibitors, that neutralize the functional activity of coagulation factors, impact patient access to a safe and effective care and predispose them to an increased risk of morbidity and mortality. ${ }^{11}$ The introduction of drugs which bypass the functional activity of FVIII and IX-such as activated prothrombin complex concentrates (APCC) (factor eight inhibitor bypassing activity [FEIBA]) and recombinant activated FVII (rFVIIa, NovoSeven, Bagsvaerd, Denmark)-has dramatically improved the management of acute bleeding in inhibitor patients, allowing home treatment and a substantial amelioration of their quality of life. ${ }^{12}$ Program of bleeding prophylaxis based on the use of bypassing agents is also being explored. ${ }^{13,14}$

Recently, new technological developments led to the production of coagulation factors endowed with a longer plasma life that, by reducing factor infusion frequency, are likely to increase patient adherence to prophylaxis. ${ }^{15}$ To date, two extended half-life coagulation proteins have been licensed by the US Food and Drug Administration: the Fc- fusion recombinant FIX (Alprolix, Biogen Idec, Weston, $\mathrm{MA}),{ }^{16}$ and the Fc-fusion recombinant FVIII (Eloctate, Biogen Idec), ${ }^{17}$ which has also been approved by the European Medicines Agency. In addition, several other extended halflife coagulation factors are in advanced phases of clinical development. ${ }^{15}$ Although several narrative reviews have focused on these newer FVIII and FIX, ${ }^{18-22}$ less is known about alternative pharmacological therapies not based on the replacement of deficient FVIII or FIX ( - Table 1). Their therapeutic potential applies not only to patients who developed an inhibitor and are thus unresponsive to factor replacement therapy: being devoid of FVIII and FIX, these agents are potentially useful to prevent inhibitor development in previously untreated patients (PUPs); being deliverable subcutaneously, they may also facilitate the implementation of prophylaxis since early childhood. Until now, these novel therapeutic approaches are based on drugs that enhance hemostasis bypassing FVIII and FIX deficiency, inhibiting naturally occurring anticoagulant pathways,

Table 1 Novel non-FVIII or FIX therapeutic approaches for the hemophilias

\begin{tabular}{|c|c|c|c|c|}
\hline Product & Company & Technology & Stage of development & Main characteristics \\
\hline rFVIIa-FP & $\begin{array}{l}\text { CSL Behring } \\
\text { (Marburg, Germany) }\end{array}$ & $\begin{array}{l}\text { Fusion protein } \\
\text { with albumin }\end{array}$ & Phase II/III study ongoing & Prolonged half-life $(8.5 \mathrm{~h})$ \\
\hline ACE910 & $\begin{array}{l}\text { Chugai } \\
\text { Pharmaceuticals/La } \\
\text { Roche Hoffman } \\
\text { (Tokyo, Japan) }\end{array}$ & $\begin{array}{l}\text { Chimeric bispecific } \\
\text { humanized antibody }\end{array}$ & $\begin{array}{l}\text { Phase I study ongoing } \\
\text { (interim analysis published) }\end{array}$ & $\begin{array}{l}\text { Prolonged half-life ( } 2 \text { wk) } \\
\text { SC weekly administration } \\
\text { reduced ABR } \\
\text { in hemophiliacs }\end{array}$ \\
\hline Concizumab & $\begin{array}{l}\text { Novo Nordisk } \\
\text { (Bagsvaerd, Denmark) }\end{array}$ & $\begin{array}{l}\text { Humanized monoclonal } \\
\text { antibody }\end{array}$ & $\begin{array}{l}\text { Phase I studies } \\
\text { (Explorer 1-3) }\end{array}$ & $\begin{array}{l}\text { Prolonged half-life } \\
\text { ( } 31.1-74.2 \text { h) } \\
\text { SC or IV administration } \\
\text { improved thrombin } \\
\text { generation and reduced } \\
\text { TFPI levels for } \geq 14 \\
\text { d in hemophiliacs }\end{array}$ \\
\hline ALN-AT3 & $\begin{array}{l}\text { Alnylam Pharmaceuticals } \\
\text { (Cambridge, MA) }\end{array}$ & SiRNA & $\begin{array}{l}\text { Phase I study } \\
\text { (interim analysis } \\
\text { published) }\end{array}$ & $\begin{array}{l}\text { SC administration } \\
\text { improved thrombin } \\
\text { generation, } \\
\text { whole blood clot } \\
\text { formation, and reduced } \\
\text { antithrombin levels to 20\% } \\
\text { in hemophilia patients }\end{array}$ \\
\hline${ }^{\text {superFVa }}$ & - & $\begin{array}{l}\text { Bioengineered } \\
\text { FVa variant }\end{array}$ & Preclinical phase & $\begin{array}{l}\text { Increased thrombin } \\
\text { generation in acquired } \\
\text { hemophilia models } \\
\text { Synergistic effect with } \\
\text { rFVIla }\end{array}$ \\
\hline $\mathrm{FXa}^{116 \mathrm{~L}}$ & - & $\begin{array}{l}\text { Bioengineered } \\
\text { zymogen-like } \\
\text { FXa variant }\end{array}$ & Preclinical phase & $\begin{array}{l}\text { Longer lasting plasma } \\
\text { activity than wild-type } \\
\text { FXa ( } 60 \text { min Vs. } 1 \text { min) } \\
\text { Increased thrombin } \\
\text { generation in hemophilia } \\
\text { models }\end{array}$ \\
\hline FXIII & $\begin{array}{l}\text { CSL Behring } \\
\text { (Marburg, Germany) }\end{array}$ & $\begin{array}{l}\text { Plasma-derived } \\
\text { product }\end{array}$ & Preclinical phase & $\begin{array}{l}\text { Long half-life }(9 \mathrm{~d}) \\
\text { Improve clot stability } \\
\text { alone or in association } \\
\text { with rFVIla }\end{array}$ \\
\hline
\end{tabular}

Abbreviations: ABR, annualized bleeding rate; F, factor; IV, intravenous; pdFXIII, plasma-derived factor XIII; rFVIla, recombinant activated factor VII; rFVIIa-FP, recombinant activated factor VII fusion protein; SC, subcutaneous; siRNA, short-interfering RNA; TFPI, tissue factor pathway inhibitor. 
potentiating the activity of some coagulation factors or rendering fibrin clots resistant to degradation.

\section{Search Methods}

For this narrative review, we analyzed the medical literature for published studies on novel therapeutic approaches for hemophilia treatment. The Medline electronic database was searched without temporal limits using English language as a restriction. The medical subject heading and keywords used were "newer hemostatic agents," "novel hemostatic agents," "investigational drugs," "hemophilia A," "hemophilia B," "inhibitors," "by-passing agents," "rFVIIa," "fusion protein," "rFVIIa-FP," “hBS23," “ACE910," “antithrombotic pathway," "anticoagulant pathway," "tissue factor pathway inhibitor (TFPI)," “concizumab," "antithrombin," "RNA interference (RNAi)," “ALN-AT3," “FV variant," and "FXIII." We also screened the reference lists of the most relevant review articles for additional studies not captured in our initial literature search. Search terms were also applied to abstracts from the latest international congresses on hemostasis and thrombosis and hematology.

\section{Bypassing Agents}

\section{Recombinant Activated Factor VII-Albumin Fusion Protein}

rFVIIa has been used for many years to treat acute bleeding in those patients with hemophilias A and B who are unresponsive to replacement therapy owing to the development of allo- or autoantibodies neutralizing the infused coagulation factors (inhibitors). The very short half-life ( 2.4 hours) of rFVIIa represents the main drawback to its use because this bypassing agent requires repeated doses given at 2- to 3-hour intervals to stop bleeding, so that its application in the frame of prophylactic regimens is limited. ${ }^{12}$

To improve rFVIIa half-life and/or efficacy, several bioengineered rFVIIa molecules have been recently developed. For two of them (the rFVIIa variant BAY86-6150 [Bayer Healthcare AG, Leverkusen, Germany] and the rFVIIa analogue vatreptacog alfa [Novo Nordisk]), the development was prematurely interrupted because of the occurrence of neutralizing antidrug antibodies. ${ }^{23,24}$ The newest bioengineered rFVIIa currently in clinical trials is a recombinant fusion protein (rFVIIa-FP, CSL Behring, Marburg, Germany), in which recombinant human albumin has been fused to the C-terminus of rFVIIa by means of a flexible glycine-serine linker. ${ }^{15}$ Pharmacokinetic (PK) studies in rodents indicated that the half-life of rFVIIa-FP was 5.8-fold longer and recovery was 1.4-fold higher than those of rFVIIa. ${ }^{25}$ Further investigations of PK parameters in mouse, rat, rabbit, and monkey models of hemophilia A confirmed the prolonged half-life, enhanced recovery, and reduced clearance. Hemostatic efficacy was maintained in rVIIa-FP-treated animals for as long as 12 hours after administration, whereas at the same time interval, it was negligible for rFVIIa-treated animals. ${ }^{26}$ No safety issues were described in these studies. In humans, a phase I double-blind study showed that rFVIIa-FP was well tolerated after a single dose administered to 40 healthy individuals, with no development of FVII inhibitors nor of antidrug antibodies. ${ }^{27}$ Half-life was increased to 8.5 hours with a dose of $1,000 \mu \mathrm{g} / \mathrm{kg}$, and clearance reduced by three- to fourfold. ${ }^{27} \mathrm{~A}$ phase II/III trial investigating PK, safety, and efficacy is currently recruiting patients with hemophilia A or B (ClinicalTrials.gov Identifier: NCT02484638). All in all, this innovative fusion product promises to be able, owing to its longer plasma half-life, to make possible with less frequent infusions treatment and prophylaxis of bleeding in hemophilic patients with FVIII or IX inhibitors. In addition, this new bypassing agent might be considered in PUPs at high risk of inhibitor formation as an option to start early prophylaxis. The bypassing approach was previously attempted with the aim of delaying the introduction of replacement treatment in 11 PUPs who first started on demand treatment with rFVIIa; however, only three children continued such regimen, while the remaining eight patients required early FVIII treatment to control bleeding and five developed a FVIII inhibitor. ${ }^{28}$

\section{ACE910}

This product consists of a chimeric bispecific humanized antibody directed against FIXa and FX, (hBS23), which mimics the cofactor function of FVIII. hBS23 binds to the enzyme FIXa with one arm and to the FX zymogen with the other, placing both in spatially appropriate positions and thereby promoting FIXa-catalyzed FX activation and tenase formation. ${ }^{18}$ In a PK study on a primate model of acquired hemophilia A, a single intravenous or subcutaneous administration of hBS23 at a dose of $3 \mathrm{mg} / \mathrm{kg}$ reduced bleeding symptoms and showed a long half-life of 14 days and subcutaneous bioavailability of nearly $100 \%$, with no development of anti-FVIII inhibitors. ${ }^{29}$ The same Japanese group successively identified an improved variant of this bispecific antibody, (ACE910, Chugai Pharmaceuticals Co., Tokyo, Japan). In a short-term primate model of acquired hemophilia A, ACE910 given as single intravenous boluses of 1 or $3 \mathrm{mg} / \mathrm{kg}$ did control artificially induced muscle or subcutaneous bleeds to the same degree as recombinant porcine FVIII (rpFVIII) infused at twice-daily intravenous doses of $10 \mathrm{U} / \mathrm{kg} .^{30}$ In a long-term primate model of acquired hemophilia A, weekly subcutaneous doses of ACE910 (initially $4 \mathrm{mg} / \mathrm{kg}$ followed by $1 \mathrm{mg} / \mathrm{kg}$ ) prevented bleeding episodes, including joint bleeding, ${ }^{31}$ making this agent potentially attractive for prophylactic use in both inhibitor and noninhibitor patients.

An open-label phase I study was completed recently in 64 healthy adult male volunteers and 18 Japanese hemophilia patients with and without inhibitors who received onceweekly subcutaneous administration of ACE910 at doses of $0.3,1$, or $3 \mathrm{mg} / \mathrm{kg}$. An interim analysis (9.5 months of followup), presented at the 2015 Congress of the International Society of Thrombosis and Hemostasis (ISTH) held in Toronto, showed increased thrombin generation together with shortening of the activated partial thromboplastin time in all patients. ${ }^{32}$ In addition, this agent at a weekly dose of $3 \mathrm{mg} /$ $\mathrm{kg}$ reduced the median annualized bleeding rate from 15.2 episodes before ACE910 to zero. ${ }^{31}$ All in all, this antibody mimicking the role of FVIII in the formation of tenase has the 
potential to be therapeutically useful to prevent bleeding in patients with actual FVIII inhibitors, for whom optimization of prophylactic regimens is still an unmet need, and in the population of patients with severe hemophilia A and hemophilia $B$ at risk to develop an inhibitor.

\section{Inhibition of Anticoagulant Pathways}

\section{Anti-tissue Factor Pathway Inhibitor Antibody}

TTP is the main negative regulator of tissue factor (TF)initiated coagulation. ${ }^{33}$ A humanized monoclonal antibody against TFPI, concizumab (mAb 2021, Novo Nordisk), with a high affinity for the KPI-2 (Kunitz-type protease inhibitor) domain of TFPI (the binding site of FXa) has been produced. By preventing FXa binding to TFPI, concizumab also prevents TFPI inhibition of the TF-FVIIa complex, resulting in enhanced tenase and thrombin formation. ${ }^{34}$ In a rabbit hemophilia model, intravenous or subcutaneous concizumab significantly reduced cuticle bleeding, with an effect comparable to that of rFVIIa. ${ }^{35}$ In a phase I randomized study (Explorer 1) conducted in 24 hemophilia A and B patients and 28 healthy volunteers, escalating doses of concizumab (250-9,000 $\mathrm{mg} / \mathrm{kg}$ intravenously or $1,000-3,000 \mu \mathrm{g} / \mathrm{kg} \mathrm{sub}-$ cutaneously) produced detectable plasma levels of the monoclonal antibody for up to 43 days, with a reduction in TFPI plasma concentrations and functional activity for 14 or more postdosing days. ${ }^{36}$ There were no serious adverse events and no anti concizumab antibody developed. In a multicenter, open-label, multiple dosing phase I clinical trial (Explorer 2), concizumab administered to four healthy males $(250 \mu \mathrm{g} / \mathrm{kg}$ every other day for eight times) improved thrombin generation, with antibody plasma levels correlating directly with thrombin generation and inversely with TFPI levels. ${ }^{37}$

A phase I, multicenter, randomized, placebo-controlled, double-blind trial investigating safety, PK, and pharmacodynamics of multiple doses of concizumab administered subcutaneously to hemophilia A persons (Explorer 3) is currently ongoing (ClinicalTrials.gov Identifier: NCT02490787). All in all, the subcutaneous administration of this product along with its long plasma half-life (31.1-74.2 hours) and lack of inhibitor development against coagulation factors make concizumab a potentially effective agent for preventing bleeding in hemophilia patients, irrespective of their severity or inhibitor status. Two additional anti-TFPI agents are currently under investigation in phase I studies conducted in subjects with severe hemophilias A and B with and without inhibitors (BAY 1093884, Bayer Healthcare; ClinicalTrials.gov Identifier: NCT02571569) and in healthy subjects (PF-0674186, Pfizer, Sandwich, United Kingdom; ClinicalTrials.gov Identifier: NCT02531815). Another approach to treat the hemophilias targeting TFPI was based on the aptamer ARC19499. Because of its in vivo activity as a procoagulant, this aptamer was evaluated in a phase I clinical study in hemophilia patients. Unfortunately, the study was interrupted owing to an increased rate of bleeding, perhaps because binding to TFPI decreases the aptamer clearance, leading to an actual increase of TFPI in patient plasma and thus to heightened naturally occurring anticoagulant activity. ${ }^{38}$

\section{Inhibition of Antithrombin}

Another appealing therapeutic approach in hemophilia involves the inhibition of the main naturally occurring anticoagulant antithrombin, which acts by inactivating FXa and thrombin. This approach was experimentally supported by results obtained in a mouse model of hemophilia $A$, showing that reduction of the plasma levels of antithrombin improved thrombin generation and was associated with a less severe bleeding phenotype. ${ }^{39}$ Exploiting RNAi, that is, the natural process of gene silencing that occurs in various organisms including plants and mammalians, the short-interfering RNA ALN-AT3 (Alnylam Pharmaceuticals, Cambridge, MA) has been developed to suppress antithrombin synthesis in hepatocytes. $^{40}$ In a preclinical study, ALN-AT3 administered subcutaneously showed potent, dose-dependent, and durable reduction of antithrombin plasma levels in various animal models of hemophilia. ${ }^{41}$ Notably, in nonhuman primate models weekly subcutaneous doses of $0.125 \mathrm{mg} / \mathrm{kg}$ led to a $50 \%$ reduction in antithrombin, whereas much higher weekly doses of $1.5 \mathrm{mg} / \mathrm{kg}$ led to a near-complete plasma antithrombin deficiency. ${ }^{40}$ A phase I study (ClinicalTrials.gov Identifier: NCT02035605) based on the subcutaneous administration of ALN-AT3 has been initiated in healthy volunteers and patients with severe or moderate hemophilia A or B. An interim analysis presented at the most recent ISTH Congress showed that in healthy volunteers, the administration of ALN-AT3 (30 $\mu \mathrm{g} / \mathrm{kg}$ ) produced a reduction of antithrombin stable and durable for more than 60 days. ${ }^{42}$ Importantly, 3 weekly doses $(15-45 \mu \mathrm{g} / \mathrm{kg})$ of ALN-AT3 were safe and well tolerated in hemophilia A patients and reduced antithrombin levels by $80 \%$ of normal, with increased thrombin generation and improved whole blood clot formation. ${ }^{42}$ All in all, the potential for low volume subcutaneous administration, infrequent dosing, and applicability to persons with hemophilia with or without inhibitors makes ALN-AT3 an encouraging investigational therapy. So far, the fear that pharmacological reduction of the plasma levels of the main naturally occurring anticoagulant protein may increase the risk of venous thromboembolism did not materialize, but more experience is warranted for reassurance.

\section{Enhancement of Coagulation Factor Activity}

\section{Factor V Variant}

The gain-of-function mutation at Arg 506 in the FV gene (i.e., FV Leiden) results in failure of inactivation by activated protein C (APC) and causes a thrombotic tendency. Several experimental and clinical studies have shown that the coinheritance of FV Leiden is able to mitigate the bleeding phenotype of severe hemophilia. ${ }^{43}$ With this background a bioengineered FVa ( $\left.{ }^{\text {super }} \mathrm{FVa}\right)$ mutated in the APC cleavage sites (Arg506/306/679Gln) and a disulfide bond (Cys609Cys1691) between the A2 and A3 domains resulted in full APC resistance and enhanced thrombin generation. ${ }^{44}$ In a

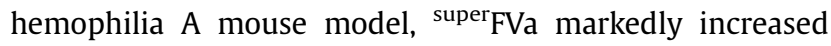
thrombin generation in vitro and in vivo and reduced bleeding more efficiently than wild type FVa used as a comparator. ${ }^{45}$ In addition, in a tail clip study performed in hemophilia 
A mice as the dose of ${ }^{\text {super }} \mathrm{FVa}$ increased from 10 to $40 \mathrm{U} / \mathrm{kg}$ blood loss decreased, and further decreased upon the addition of rFVIIa (from 1 to $3 \mathrm{mg} / \mathrm{kg}$ ), suggesting a synergistic effect of the two products. ${ }^{46}$ Similar beneficial effects of ${ }^{\text {super }} \mathrm{FVa}$ and rFVIIa in terms of thrombin generation improvement were observed in plasma samples of hemophilia $A$ patients with inhibitors. ${ }^{46}$ These preclinical studies suggest that ${ }^{\text {super }}$ FVa has the potential for becoming a useful agent for the treatment of bleeding in hemophilia patients with inhibitors, but at variance with previous products early studies in human are currently lacking.

\section{Factor X Variant}

Blood coagulation FX plays a central role in the coagulation cascade being the principal physiological substrate for the extrinsic (TF/FVIIa) and intrinsic (FVIIIa/FIXa) tenase complex, thus linking the two coagulation pathways. Because FXa appears a particularly suitable candidate to bypass deficiencies of FVIII and FIX in the intrinsic pathway, its therapeutic use has been evaluated during the last two decades in hemophilia persons with inhibitors. ${ }^{47,48}$ However, its short half-life and potential for systemic hypercoagulability rendered this product clinically unusable. Recently, a bioengineered FXa variant with a single amino acid change at position 16 in the $\mathrm{N}$ terminus of the heavy chain (FXa ${ }^{\mathrm{I} 16 \mathrm{~L}}$ ) was produced. ${ }^{49}$ This protein, with a zymogen-like conformation, is characterized by a prolonged half-life in human plasma and structural alterations in the active site that confer resistance of FXa to inactivation by antithrombin and TFPI. ${ }^{50}$ In addition, FXa ${ }^{\mathrm{I} 16 \mathrm{~L}}$ is ineffective in the absence of its cofactor FVa, thus reducing the prothrombotic potential and restricting its action at the surface of activated platelets or endothelial cells. ${ }^{51}$ Binding to FVa, it rescues procoagulant activity and causes a transition from the zymogen to the active protease, with full thrombin generation. ${ }^{50}$ In an acute tail bleeding murine model, the intravenous administration of $\mathrm{FXa}^{\mathrm{I} 16 \mathrm{~L}}$ (escalating doses: 1$200 \mu \mathrm{g} / \mathrm{kg}$ ) reduced tail clip blood loss up to $69 \%{ }^{52}$ A preclinical study in hemophilic mice showed that $\mathrm{FXa}^{\mathrm{I} 16 \mathrm{~L}}$ was safe and highly efficacious after a single dose in multiple injury models. ${ }^{50}$ Moreover, it was 20- to 50-fold more effective than rFVIla in these models. ${ }^{49}$ In hemophilic plasma, FXa ${ }^{16 \mathrm{~L}}$ had a much more prolonged activity than wild-type factor Xa ( $\sim 60 \mathrm{mi}-$ nutes vs. 1 minute) and promoted robust thrombin generation bypassing the intrinsic pathway. ${ }^{49}$ Consistently with these findings, a recent study showed that $\mathrm{FXa}^{\mathrm{I} 16 \mathrm{~L}}$ restored thromboelastometry clot time to control values in whole blood from severe hemophilia A persons with and without inhibitors. ${ }^{53}$ Other FXa variants with biological properties similar to FXa ${ }^{\mathrm{I} 16 \mathrm{~L}}$ have been recently described. ${ }^{54}$ All in all, preclinical data suggest that FXa variants have a potential utility in hemophilia for the treatment of bleeding, but clinical data are totally lacking at the moment.

\section{Enhancing Fibrin Clot Resistance}

\section{Factor XIII}

Because hemophilia is characterized by abnormal thrombin generation and impaired clot stability, FXIII (which stabilizes fibrin clots by cross-linking fibrin monomers) was proposed as an alternative treatment. ${ }^{54}$ Supraphysiological concentrations of FXIII stabilize blood clots in hemophilia patients by improving resistance to tissue plasminogen activator-induced fibrinolysis, even at very low concentrations of FVIII $(<0.1 \mathrm{IU} / \mathrm{mL}) .^{55}$ The effect of FXIII combined with rFVIIa was evaluated in 14 patients with severe hemophilia, finding that clot stability was much better with this combination therapy than with rFVIIa alone. ${ }^{56}$ Owing to these in vitro studies and to its long half-life (9 days), FXIII alone or as an adjunct therapy represents an interesting option to prevent bleeding in hemophilia patients without inhibitors or to enhance the effect of bypassing agents in those with inhibitors.

\section{Conclusions}

Advances in our understanding of the molecular mechanisms of hemostasis have paved the way to the development of new therapeutic strategies for hemophilia, peculiar for being based on mechanisms other than the replacement of the deficient coagulation factor (-Table 1). ${ }^{57}$ The rationale for their development lies in the need to improve patients' adherence to prophylaxis, meant to develop more effective therapies to treat and/or prevent bleeding in patients with inhibitors and possibly reduce the occurrence of inhibitors in patients at high risk. Some of these agents currently on the development pipeline act by inhibiting naturally occurring anticoagulant proteins such as antithrombin or TFPI, bypassing FVIII or IX in tenase formation, enhancing coagulation factor activity or rendering fibrin clots more resistant to degradation. Despite different mechanisms of action, these newer molecules are generally characterized by long halflives, subcutaneous administration, no immunogenicity against FVIII, and capacity to improve thrombin generation and clot stability independently from the degree of the coagulation factor deficiency or presence of inhibitors.

If results of the ongoing clinical trials will confirm the available preliminary data regarding safety and efficacy, these hemostatic agents would represent an important progress in the therapeutic armamentarium of hemophilia. They could be used to treat or prevent bleeding episodes in patients with FVIII or FIX inhibitors, provided their potential advantages over currently available bypassing agents (rFVIIa or the APCC) are established by comparative clinical trials. Another appealing potential role pertains to the treatment or prevention of bleeding episodes in patients with hemophilia A or B without inhibitors but at risk of developing this complication, that is, the main current problem in the management of these inherited coagulation disorders. The therapeutic uses of nonreplacement therapies is emphasized by a recent randomized trial that compared the immunogenicity of plasma-derived and recombinant FVIII products in PUPs with severe hemophilia A and showed that, even though plasma-derived FVIII is less immunogenic than recombinant FVIII, the cumulative incidence of inhibitors following the infusion of the former products is still unacceptably high. ${ }^{58}$ Hence, the use of products not based on FVIII replacement to treat or prevent 
bleeding in patients at risk of developing inhibitors is potentially appealing.

Although FIX inhibitory alloantibodies are rarer than FVIII inhibitors, they are more clinically severe because in addition to refractoriness to replacement therapy approximately $50 \%$ of patients with this complication develop severe post-replacement anaphylaxis with related morbidity and mortality. All in all, the development of efficacious and safe products to treat hemophilia without replacing the deficient factor may turn to be advantageous in patients at high risk of inhibitor development. Until now the preliminary results, particularly those of ACE910, are promising because the annualized bleeding rate was minimized. However, more experience is needed to see whether or not these striking results are confirmed in larger real-life series, and how often switching to factor replacement becomes necessary for severe bleeding episodes or major surgery.

Note

A new long-acting pegylated factor VIII produced by Baxalta is now licensed. A phase 1 study of ACE 910 in healthy subjects is now published in full. ${ }^{59}$ The compound at doses up to $1 \mathrm{mg} / \mathrm{kg}$ was well tolerated and had no notable adverse hypercoagulable effect in 64 subjects.

\section{References}

1 Mannucci PM, Tuddenham EGD. The hemophilias-from royal genes to gene therapy. N Engl J Med 2001;344(23): 1773-1779

2 Berntorp E, Shapiro AD. Modern haemophilia care. Lancet 2012; 379(9824):1447-1456

3 Franchini M, Mannucci PM. Hemophilia A in the third millennium. Blood Rev 2013;27(4):179-184

4 White GC II, Rosendaal F, Aledort LM, Lusher JM, Rothschild C, Ingerslev J; Factor VIII and Factor IX Subcommittee. Definitions in hemophilia. Recommendation of the scientific subcommittee on factor VIII and factor IX of the scientific and standardization committee of the International Society on Thrombosis and Haemostasis. Thromb Haemost 2001;85(3):560

5 Franchini M, Mannucci PM. Past, present and future of hemophilia: a narrative review. Orphanet J Rare Dis 2012;7:24

6 Mannucci PM, Franchini M. Present and future challanges in the treatment of haemophilia: a clinician's perspective. Blood Transfus 2013;11(Suppl 4):s77-s81

7 Franchini M. The modern treatment of haemophilia: a narrative review. Blood Transfus 2013;11(2):178-182

8 Manco-Johnson MJ, Abshire TC, Shapiro AD, et al. Prophylaxis versus episodic treatment to prevent joint disease in boys with severe hemophilia. N Engl J Med 2007;357(6): 535-544

9 Gringeri A, Lundin B, von Mackensen S, Mantovani L, Mannucci PM; ESPRIT Study Group. A randomized clinical trial of prophylaxis in children with hemophilia A (the ESPRIT Study). J Thromb Haemost 2011;9(4):700-710

10 Franchini M, Mannucci PM. Inhibitors of propagation of coagulation (factors VIII, IX and XI): a review of current therapeutic practice. Br J Clin Pharmacol 2011;72(4):553-562

11 Astermark J, Santagostino E, Keith Hoots W. Clinical issues in inhibitors. Haemophilia 2010;16(Suppl 5):54-60
12 Franchini M, Coppola A, Tagliaferri A, Lippi G. FEIBA versus NovoSeven in hemophilia patients with inhibitors. Semin Thromb Hemost 2013;39(7):772-778

13 Gringeri A, Leissinger C, Cortesi PA, et al. Health-related quality of life in patients with haemophilia and inhibitors on prophylaxis with anti-inhibitor complex concentrate: results from the ProFEIBA study. Haemophilia 2013;19(5):736-743

14 Konkle BA, Ebbesen LS, Erhardtsen E, et al. Randomized, prospective clinical trial of recombinant factor VIIa for secondary prophylaxis in hemophilia patients with inhibitors. J Thromb Haemost 2007;5(9):1904-1913

15 Mannucci PM. Half-life extension technologies for haemostatic agents. Thromb Haemost 2015;113(1):165-176

16 Powell JS, Pasi KJ, Ragni MV, et al. BLONG Investigators. Phase 3 study of recombinant factor IX Fc fusion protein in hemophilia B. N Engl J Med 2013;369(24):2313-2323

17 Mahlangu J, Powell JS, Ragni MV, et al. ALONG Investigators. Phase 3 study of recombinant factor VIII Fc fusion protein in severe hemophilia A. Blood 2014;123(3):317-325

18 Peyvandi F, Garagiola I, Seregni S. Future of coagulation factor replacement therapy. J Thromb Haemost 2013;11(Suppl 1):84-98

19 Mannucci PM, Mancuso ME. Investigational drugs for coagulation disorders. Expert Opin Investig Drugs 2013;22(8):945-953

20 Ragni MV. New and emerging agents for the treatment of hemophilia: focus on extended half-life recombinant clotting proteins. Drugs 2015;75(14):1587-1600

21 Shetty S, Ghosh K. Novel therapeutic approaches for haemophilia. Haemophilia 2015;21(2):152-161

22 Franchini M, Favaloro EJ, Lippi G. Newer hemostatic agents. Semin Thromb Hemost 2015;41(7):802-808

23 Mahlangu JN, Koh PL, Ng HJ, Lissitchkov T, Hardtke M, Schroeder J. The TRUST trial: anti-drug antibody formation in a patient with hemophilia with inhibitors after receiving the activated factor VII product Bay 86-6150 (Abstract). Blood 2015;122(21):573

24 Mahlangu JN, Weldingh KN, Lentz SR, et al; adept ${ }^{\mathrm{TM}} 2$ Investigators; adept 2 Investigators. Changes in the amino acid sequence of the recombinant human factor VIla analog, vatreptacog alfa, are associated with clinical immunogenicity. J Thromb Haemost 2015;13(11):1989-1998

25 Weimer T, Wormsbächer W, Kronthaler U, Lang W, Liebing U, Schulte S. Prolonged in-vivo half-life of factor VIla by fusion to albumin. Thromb Haemost 2008;99(4):659-667

26 Zollner S, Schuermann D, Raquet E, et al. Pharmacological characteristics of a novel, recombinant fusion protein linking coagulation factor VIla with albumin (rVIIa-FP).J Thromb Haemost 2014; 12(2):220-228

27 Golor G, Bensen-Kennedy D, Haffner S, et al. Safety and pharmacokinetics of a recombinant fusion protein linking coagulation factor VIIa with albumin in healthy volunteers. J Thromb Haemost 2013;11(11):1977-1985

28 Rivard GE, Lillicrap D, Poon MC, et al. Can activated recombinant factor VII be used to postpone the exposure of infants to factor VIII until after 2 years of age? Haemophilia 2005;11(4):335-339

29 Kitazawa T, Igawa T, Sampei Z, et al. A bispecific antibody to factors IXa and $\mathrm{X}$ restores factor VIII hemostatic activity in a hemophilia $\mathrm{A}$ model. Nat Med 2012;18(10):1570-1574

30 Muto A, Yoshihashi K, Takeda M, et al. Anti-factor IXa/X bispecific antibody (ACE910): hemostatic potency against ongoing bleeds in a hemophilia A model and the possibility of routine supplementation. J Thromb Haemost 2014;12:206-213

31 Muto A, Yoshihashi K, Takeda M, et al. Anti-factor IXa/X bispecific antibody ACE910 prevents joint bleeds in a long-term primate model of acquired hemophilia A. Blood 2014;124(20):3165-3171

32 Shima M, Nanbusa H, Taki M, et al. Long-term safety and prophylactic efficacy of once-weekly subcutaneous administration of ACE910 in Japanese hemophilia A patients with and without FVIII inhibitors: interim results of the extension study of a phase 1 study (Abstract). J Thromb Haemost 2015;13(Suppl 2):AS017 
33 Wood JP, Ellery PE, Maroney SA, Mast AE. Biology of tissue factor pathway inhibitor. Blood 2014;123(19):2934-2943

34 Dockal M, Hartmann R, Fries M, et al. Small peptides blocking inhibition of factor Xa and tissue factor-factor VIIa by tissue factor pathway inhibitor (TFPI). J Biol Chem 2014;289(3): 1732-1741

35 Hilden I, Lauritzen B, Sørensen BB, et al. Hemostatic effect of a monoclonal antibody mAb 2021 blocking the interaction between FXa and TFPI in a rabbit hemophilia model. Blood 2012;119(24): 5871-5878

36 Chowdary P, Lethagen S, Friedrich U, et al. Safety and pharmacokinetics of anti-TFPI antibody (concizumab) in healthy volunteers and patients with hemophilia: a randomized first human dose trial. J Thromb Haemost 2015;13(5):743-754

37 Waters EK, Sigh J, Ezban M, Hilden I. Thrombin generation is increased in plasma from healthy males who have received concizumab, an antibody against tissue factor pathway inhibitor (Explorer $^{\mathrm{TM}}$ 2) (Abstract). J Thromb Haemost 2015;13(Suppl 2): AS019

38 Dockal M, Pachlinger R, Hartmann R, et al. Biological explanation of clinically observed elevation of TFPI plasma levels after treatment with TFPI-Antagonistic Aptamer BAX 499 (Abstract). Blood 2012;120:1104

39 Bolliger D, Szlam F, Suzuki N, Matsushita T, Tanaka KA. Heterozygous antithrombin deficiency improves in vivo haemostasis in factor VIII-deficient mice. Thromb Haemost 2010;103(6): 1233-1238

40 Ragni MV. Targeting antithrombin to treat hemophilia. N Engl J Med 2015;373(4):389-391

41 Sehgal A, Barros S, Ivanciu L, et al. An RNAi therapeutic targeting antithrombin to rebalance the coagulation system and promote hemostasis in hemophilia. Nat Med 2015;21(5): 492-497

42 Sorensen B, Mant T, Georgiev P, et al; on behalf of ALN-AT3 Investigators. A subcutaneously administered investigational RNAi therapeutic (ALN-AT3) targeting antithrombin for treatment of hemophilia: interim phase 1 study results in patients with hemophilia A or B. J Thromb Haemost 2015;13(Suppl 2):OR213 (abstract)

43 Franchini M, Mannucci PM. Interactions between genotype and phenotype in bleeding and thrombosis. Haematologica 2008; 93(5):649-652

44 von Drygalski A, Bhat V, Gale AJ, et al. An engineered factor Va prevents bleeding induced by anticoagulant wt activated protein C. PLoS ONE 2014;9(8):e104304

45 von Drygalski A, Cramer TJ, Bhat V, Griffin JH, Gale AJ, Mosnier LO. Improved hemostasis in hemophilia mice by means of an engineered factor Va mutant. J Thromb Haemost 2014;12(3): 363-372

46 Bhat V, von Drygalski A, Gale AJ, Griffin JH, Mosnier LO. Synergistic effect in bleed reduction by superFVa and recombinant human FVIIa in vivo suggest a novel bypassing strategy for hemophilia patients with inhibitors. Blood 2014;14(Suppl):692 (abstract)

47 Wolf DL, Lin PH, Hollenbach S, Wong A, Phillips DR, Sinha U. Procoagulant activity of reversibly acylated human factor Xa. Blood 1995;86(11):4153-4157

48 Louvain-Quintard VB, Bianchini EP, Calmel-Tareau C, Tagzirt M, Le Bonniec BF. Thrombin-activable factor $\mathrm{X}$ re-establishes an intrinsic amplification in tenase-deficient plasmas. J Biol Chem 2005; 280(50):41352-41359

49 Bunce MW, Toso R, Camire RM. Zymogen-like factor Xa variants restore thrombin generation and effectively bypass the intrinsic pathway in vitro. Blood 2011;117(1):290-298

50 Ivanciu L, Toso R, Margaritis P, et al. A zymogen-like factor Xa variant corrects the coagulation defect in hemophilia. Nat Biotechnol 2011;29(11):1028-1033

51 Camire RM. Bioengineered factor Xa as a potential new strategy for hemophilia therapy. Expert Rev Hematol 2012;5(2): 121-123

52 Reema J, Patel-Hett S, Camire RM, Fruebis J, Pittman D. A zymogenlike factor Xa improves hemostasis in a murine bleeding model. Blood 2014;14(Suppl):1476 (abstract)

53 George LA, Thalji NK, Raffini LJ, Gimotty PA, Camire RM. Correction of human hemophilia A whole blood abnormalities with a novel bypass agent: zymogen-like FXa(I16L). J Thromb Haemost 2015; 13(9):1694-1698

54 Ivanciu L, Camire RM. Hemostatic agents of broad applicability produced by selective tuning of factor Xa zymogenicity. Blood 2015;126(1):94-102

55 Rea CJ, Foley JH, Sørensen B. Factor XIII in the treatment of hemophilia A. N Engl J Med 2012;366(3):281-283

56 Rea CJ, Foley JH, Ingerslev J, Sørensen B. Factor XIII combined with recombinant factor VIIa: a new means of treating severe hemophilia A. J Thromb Haemost 2011;9(3):510-516

57 Powell JS. Lasting power of new clotting proteins. Hematology (Am Soc Hematol Educ Program) 2014;2014(1):355-363

58 Peyvandi F, Mannucci PM, Garagiola I, et al. Source of factor VIII replacement (plasmatic or recombinant) and incidence of inhibitory alloantibodies in previously untreated patients with severe hemophilia A: the multicenter randomized SIPPET study (Abstract). Blood 2015;126(23):5

59 Uchida N, Sambe T, Yoneyama K, et al. A first-in-human phase 1 study of ACE910, a novel factor VIII-mimetic bispecific antibody, in healthy subjects. Blood 2016;127:1633-1641 